\title{
Surgery for meningioma in the elderly and long-term survival: comparison with an age- and sex-matched general population and with younger patients
}

\author{
*Benjamin Brokinkel, MD, ${ }^{1}$ Markus Holling, MD, ${ }^{1}$ Dorothee Cäcilia Spille, ${ }^{1}$ Katharina Heß, MD, ${ }^{2}$ \\ Cristina Sauerland, PhD, ${ }^{3}$ Caroline Bleimüller, MD, ${ }^{4}$ Werner Paulus, MD, ${ }^{2}$ Johannes Wölfer, MD, ${ }^{1}$ \\ and Walter Stummer, MD1
}

${ }^{1}$ Department of Neurosurgery and ${ }^{2}$ Institute of Neuropathology, University Hospital Münster; and ${ }^{3}$ Institute of Biostatistics and Clinical Research and ${ }^{4}$ Department of Clinical Radiology, University of Münster, Münster, North Rhine-Westphalia, Germany

\begin{abstract}
OBJECTIVE The purpose of this study was to compare long-term prognosis after meningioma surgery in elderly and younger patients as well as to compare survival of elderly patients with surgically treated meningioma to survival rates for the general population.
\end{abstract}

\begin{abstract}
METHODS Five hundred meningioma patients (median follow-up 90 months) who underwent surgery between 1994 and 2009 were subdivided into "elderly" (age $\geq 65$ years, $n=162$ ) and "younger" (age < 65 years, $n=338$ ) groups for uni- and multivariate analyses. Mortality was compared with rates for the age- and sex-matched general population.
\end{abstract}

RESULTS The median age at diagnosis was 71 in the elderly group and 51 years in the younger group. Sex, intracranial tumor location, grade of resection, radiotherapy, and histopathological subtypes were similar in the 2 groups. Highgrade (WHO Grades II and III) and spinal tumors were more common in older patients than in younger patients (15\% vs $8 \%, p=0.017$, and $12 \%$ vs $4 \%, p=0.001$, respectively). The progression-free interval (PFI) was similar in the 2 groups, whereas mortality at 3 months after surgery was higher and median overall survival (OS) was shorter in older patients $(7 \%, 191$ months) than in younger patients (1\%, median not reached; HR 4.9, 95\% Cl 2.75-8.74; $p<0.001)$. Otherwise, the median OS in elderly patients did not differ from the anticipated general life expectancy $(\mathrm{HR} 1.03,95 \% \mathrm{Cl} 0.70-1.50$; $\mathrm{p}=0.886)$. Within the older patient group, $\mathrm{PFI}$ was lower in patients with high-grade meningiomas ( $\mathrm{HR} 24.74,95 \% \mathrm{Cl}$ 4.23-144.66; $p<0.001$ ) and after subtotal resection (HR 10.57, 95\% Cl 2.23-50.05; $p=0.003)$. Although extent of resection was independent of perioperative mortality, the median OS was longer after gross-total resection than after subtotal resection (HR 2.7, 95\% Cl 1.09-6.69; $p=0.032$ ).

CONCLUSIONS Elderly patients with surgically treated meningioma do not suffer from impaired survival compared with the age-matched general population, and their PFI is similar to that of younger meningioma patients. These data help mitigate fears concerning surgical treatment of elderly patients in an aging society.

https://thejns.org/doi/abs/10.3171/2016.2.JNS152611

KEY WORDS meningioma; geriatric; prognosis; WHO grade; Simpson classification; oncology

$\mathrm{M}$ ENINGIOMAS are the most frequent primary intracranial neoplasms, accounting for more than one-third of all CNS tumors. Large epidemiological studies report a median patient age at diagnosis of 65 years and a rising incidence of meningiomas especially among elderly patients. ${ }^{2,5,13,20,21}$ Numerous analyses have shown increased perioperative mortality and morbidity in elderly patients compared with younger patients undergo- ing meningioma surgery, $3,4,7,14,16,18,25,26,30,32$ but these studies mainly focused on the perioperative phase, with followup data for a maximum of 1 year after surgery. In 3 retrospective analyses of elderly meningioma patients with 5-year follow-up by Cohen-Inbar and Caroli et al., the reported rates of recurrence were $8 \%, 24 \%$, and $17 \%$, with mortality rates of $4 \%-16 \%,{ }^{6,89}$ but none of these studies discriminated tumor-related mortality from the inherent,

ABBREVIATIONS EOR = extent of resection; GTR = gross-total resection; HR = hazard ratio; OR = odds ratio; OS = overall survival; PFI = progression-free interval; STR

= subtotal resection

SUBMITTED November 11, 2015. ACCEPTED February 22, 2016.

INCLUDE WHEN CITING Published online June 3, 2016; DOI: 10.3171/2016.2.JNS152611.

* Drs. Brokinkel and Holling contributed equally to this work. 
tumor-independent reduced life expectancy of elderly patients. The analyses focused on clinical and radiological scoring systems. They included only sparse data on mortality, recurrence, follow-up periods, and histopathological data (e.g., WHO grades in one study) and lacked long-term and comparative analyses between younger and elderly patients. In addition, elderly meningioma patients have a higher incidence of atypical and malignant meningiomas ${ }^{22}$ which requires separate discussions concerning risks and benefits of surgical treatment within this highrisk patient population.

In this study, we retrospectively analyzed all meningioma cases involving patients who underwent surgery in our department within a 15-year period and conducted subgroup analyses for patients 65 years and older compared with younger patients with respect to histopathological grade and subtype, tumor location, and grade of resection and their influence on long-term tumor recurrence and mortality. Mortality among older patients was compared with the mortality and age- and sex-adjusted life expectancy in the general German population in a case-control study.

\section{Methods \\ Data Collection}

The archives of the Institute of Neuropathology, Münster, Germany, were reviewed for all cases of histopathologically diagnosed meningiomas resected at our department (Department of Neurosurgery, University Hospital Münster) between May 1994 and April 2009. The end of the inclusion period was chosen to allow an interval of at least 5 years between the date of surgery and the date of data collection (May 2014) for sufficiently long follow-up. In all cases, surgery was indicated for treatment of space-occupying and/or symptomatic lesions in the absence of contraindications against either microsurgery or anesthesia, e.g., a life expectancy of only months due to another malignant neoplasm or newly diagnosed life-threatening cardiovascular events. Meningioma subtype and histopathological grading according to the 1993, 2000 , and 2007 WHO criteria ${ }^{15,19,24}$ were determined from neuropathological reports. Baseline medical data, including patients' sex and age at the time of surgery, tumor location, and grade of resection according to the Simpson classification system, ${ }^{28}$ were obtained from medical and operative reports in each individual case. Tumor location was classified as falx, convexity, sphenoid ridge, tuberculum sellae, frontobasal, petroclival, intraventricular, posterior fossa, or spinal. Maximum safely achievable tumor resection/reduction was performed in all patients. Unless contraindications were present (e.g., low Karnofsky Performance Status or refusal by the patients), adjuvant radiation therapy was recommended in all cases of Grade III and subtotally resected atypical meningiomas as well as for benign lesions after simple surgical decompression. No chemotherapy was administered.

As is standard in our institution, routine postoperative care included follow-up clinical examinations and gadolinium-enhanced MRI at 3 and 6 months after surgery. Images were analyzed for tumor progression by a team of at least 2 independent observers, including 1 neurosurgeon and 1 radiologist (or neuroradiologist). Tumor size was evaluated by the 2 independent observers, and progression was considered present if an increase greater than the MRI or CT resolution capacity was identified by both of them. Unless no tumor progression is reported, patients with Grade I and high-grade meningiomas are usually followed up with annual imaging studies and semiannual clinical examination. Contrast-enhanced CT scans are performed when there is any contraindication against MRI.

Follow-up data were retrieved from medical reports from our department and updated by means of a standardized questionnaire sent to the primary caretakers. Data collection and scientific use were approved by the university ethics committee (ethics committee of the Westfälische Wilhelms-Universität Münster). All patients had been asked for approval for potential use of their anonymized clinical data for future analyses when informed consent was obtained for surgery, as is standard at our institution.

\section{Statistical Analyses}

Calculations were performed using commercial statistical software (IBM SPSS Statistics, version 22). Data are described by standard statistics-i.e., absolute and relative frequencies for categorical variables and median and range for continuous variables. Distributions of time-toevent variables were estimated by the Kaplan-Meier method and further characterized by 3-month (perioperative) survival rates and 5- and 10-year survival and progression rates. Progression was defined as radiological progression with or without subsequent indication for further treatment. The progression-free interval (PFI) was calculated from the date of initial surgery to the date of radiologically confirmed tumor progression. Overall survival (OS) was defined as the interval between date of surgery and date of death from any cause. Unless otherwise specified, mortality was considered the rate of non-disease-specific deaths in a defined group (e.g., patients with Grade I meningiomas) within a specified period. Patients lacking data on mortality or progression were excluded from corresponding analyses. Fisher's exact tests and Mann-Whitney Utests were performed for comparing categorical and continuous variables, respectively. Actuarial data (OS, PFI) were compared between groups by means of log-rank tests (Mantel-Cox test).

For outcome parameters (PFI, OS, recurrence, mortality), the following variables were tested in a multivariate analysis using Cox proportional hazards models: age $(<65$ [ref] vs $\geq 65$ years), sex (male [ref] vs female), WHO grade (classified into Grade I [ref] vs Grade II and III), tumor location (classified into convexity [ref], skull base, falx, spinal, intraventricular) and extent of resection (EOR, classified into Simpson Grade I and II [ref] vs III and IV). The results of uni- and multivariable analysis of OS and PFI are described with hazard and odds ratios (HR and OR), the respective 95\% confidence intervals, and Waldtest $p$ values. Population-based analyses were performed to compare survival between patients and average life expectancy within the general German population, based on data published by the German Federal Office of Statistics (Statistisches Bundesamt Deutschland, DESTATIS, Wiesbaden, Germany). ${ }^{11}$ A 2 -sided p value $<0.05$ was consid- 
ered to be statistically significant in all analyses. Subgroup analyses for elderly patients (age $\geq 65$ years) were supplemented by comparative analyses with younger patients (age $<65$ years).

\section{Results}

Between May 1994 and April 2009, 533 patients underwent surgery for histopathologically confirmed spinal or intracranial meningiomas. Among those, 500 patients (94\%) with a median age of 58 years (range 7-87 years), including 357 females (71\%) and 143 males (29\%; female/ male ratio 2.5:1) were undergoing initial resection of a meningioma (94\%), whereas 33 patients $(6 \%)$ were operated on for tumor recurrence. Within the 15 -year inclusion period, the percentage of individuals who were 65 years or older increased from $27 \%$ in the 1st year to $38 \%$ in the last 4 years (43 of 158 and 73 of 191 patients, respectively). A total of 177 (33\%) of 533 operations were performed in patients 65 years and older, with 92\% (162) of these 177 operations being for primarily diagnosed tumors and 15 $(8 \%)$ being for recurrences. The 33 patients $(6 \%)$ who were operated on for recurrence were not included in further statistical analyses.

\section{Subgroup Analyses of Elderly Patients}

Table 1 summarizes the data from the 500 patients who were undergoing a first resective surgery for treatment of meningioma, stratified by age $(<65$ vs $\geq 65$ ). Demographic data (age, sex) and baseline clinical data (tumor location, histopathological grading, and subtype) were available for all patients. Of the 500 patients, 162 were 65 years or older, and these patients constituted the elderly group. This group included 112 women (69\%) and 50 men (31\%; female/male ratio 2.2) with a median age of 71 years (range 65-87). The grade of resection according to the Simpson classification system could be determined in 152 cases $(94 \%)$.

\section{WHO Grade}

Tumor grading according to the WHO criteria was available in all 162 patients in the elderly group and included 138 Grade I, 19 (atypical) Grade II, and 5 (anaplastic) Grade III meningiomas (accounting for 85\%, $12 \%$, and $3 \%$ of cases, respectively). The frequency of high-grade meningiomas did not differ significantly when graded according to the 1993, 2000, and 2007 WHO classifications $\left(8 \%, 13 \%\right.$, and $11 \%$, respectively).$^{15,19,24}$ Grade II and III meningiomas were found more commonly in male patients (24\% [12 cases in 50 patients]) than in female patients ( $11 \%$ [12 cases in 112 patients], $\mathrm{p}=0.034)$, and WHO grade was strongly correlated with tumor location ( $\mathrm{p}<0.001$ ). Thus, all spinal and $94 \%$ of the skull base meningiomas $(n=64)$ but $74 \%$ of the meningiomas arising from the falx and the convexity $(n=12$ and $n=42$, respectively) were diagnosed as Grade I tumors. Accordingly, only $6 \%$ of the skull base $(n=4)$ but $25 \%$ and $19 \%$ of all falx and convexity tumors were atypical meningiomas. Of the 5 anaplastic meningiomas, 4 were localized at the convexity, and 1 was intraventricular. In the 156 cases with follow-up data (96\%), postoperative radiation therapy
TABLE 1. Comparison of demographic and clinical characteristics of elderly and younger patients*

\begin{tabular}{|c|c|c|c|}
\hline Characteristic & $\begin{array}{l}\text { Older Patients } \\
\quad(\geq 65 \mathrm{yrs})\end{array}$ & $\begin{array}{c}\text { Younger Patients } \\
(<65 \mathrm{yrs})\end{array}$ & $\begin{array}{c}p \\
\text { Valuet }\end{array}$ \\
\hline No. of patients & 162 & 338 & \\
\hline Sex & & & NS \\
\hline $\mathrm{F}$ & $112(69)$ & $245(73)$ & \\
\hline M & $50(31)$ & $93(27)$ & \\
\hline \multicolumn{4}{|l|}{ Age in yrs } \\
\hline Median & 71 & 51 & \\
\hline Range & $65-87$ & $7-64$ & \\
\hline Tumor location & & & NS \\
\hline Convexity & $57(35)$ & $116(34)$ & \\
\hline Falx & $16(10)$ & $50(15)$ & \\
\hline Sphenoid ridge & $22(14)$ & $55(16)$ & \\
\hline Posterior fossa & $15(9)$ & $43(13)$ & \\
\hline Tuberculum sellae & $3(2)$ & $5(2)$ & \\
\hline Frontobasal & $26(16)$ & $43(13)$ & \\
\hline Intraventricular & $1(1)$ & $6(2)$ & \\
\hline Petroclival & $2(1)$ & $7(2)$ & \\
\hline Spinal & $20(12)$ & $13(4)$ & 0.002 \\
\hline EOR (Simpson grade) & & & NS \\
\hline Grade I & $58(38)$ & $112(36)$ & \\
\hline Grade II & $59(39)$ & $133(42)$ & \\
\hline Grade III & $30(20)$ & $57(18)$ & \\
\hline Grade IV & $5(3)$ & $13(4)$ & \\
\hline Grade V & $0(0)$ & & \\
\hline WHO grade & & & $0.006 \ddagger$ \\
\hline Grade I & $138(85)$ & $312(92)$ & \\
\hline Angiomatous & $2(1)$ & $4(1)$ & \\
\hline Transitional & $34(21)$ & $83(25)$ & \\
\hline Meningothelial & $83(51)$ & $187(56)$ & \\
\hline Microcystic & $1(1)$ & $3(1)$ & \\
\hline Fibrous & $11(7)$ & $24(7)$ & \\
\hline Psammomatous & $3(2)$ & $1(0.3)$ & \\
\hline Secretory & $3(2)$ & $6(2)$ & \\
\hline Metaplastic & $1(1)$ & $0(0)$ & \\
\hline Grade II (atypical) & $19(12)$ & $25(7)$ & \\
\hline Clear cell & $0(0)$ & $1(0.6)$ & \\
\hline Chordoid & $0(0)$ & $2(0.3)$ & \\
\hline Grade III (anaplastic) & $5(3)$ & $1(0.3)$ & \\
\hline \multicolumn{4}{|l|}{ Outcome } \\
\hline Progression & $16(11)$ & $55(17)$ & NS \\
\hline Death & $36(22)$ & $19(6)$ & $<0.001$ \\
\hline w/in 3 mos & $12(7)$ & $3(1)$ & $<0.001$ \\
\hline w/in 5 yrs & $23(14)$ & $10(3)$ & $<0.001$ \\
\hline w/in 10 yrs & $31(19)$ & $15(5)$ & $<0.001$ \\
\hline
\end{tabular}

NS = not significant.

* Summary of demographic and baseline clinical data and follow-up data for patients 65 years or older and patients younger than 65 years.

$\dagger$ For comparison of clinical variables between older and younger individuals.

‡ Comparing WHO grades excluding histological subtypes. 
was administered to 10 individuals (6\%); 2 of these patients had Grade I tumors (representing $2 \%$ of the Grade II tumors in the elderly patient group), 6 had Grade II tumors (33\% of the Grade II tumors in the group), and 2 had Grade III tumors ( $40 \%$ of the Grade III tumors in the group) (p < 0.001).

\section{Tumor Location and Grade of Resection}

Rates of recurrence varied widely among various locations and were highest in tuberculum sellae and posterior fossa meningiomas (67\% [2 of 3] and 15\% [2 of 13], respectively) and lower in falx (13\% [2 of 15]), convexity (10\% [5 of 50]), and frontobasal (9\% [2 of 22]) tumors, while no recurrences were observed in 17 spinal tumors $(\mathrm{p}=0.048)$. There was no correlation between tumor location and other prognostic factors. Among 152 patients with data available on the grade of tumor resection, meningiomas were gross-totally removed in 117 cases $(77 \%$, Simpson Grades I and II) and partially resected in 35 (23\%, Simpson Grades III and IV, Table 1). There was no case of simple decompression (Simpson Grade V). Extent of resection was found to be independent of tumor location, WHO grade, and patients' age or sex. There were no sex-dependent differences in grades of resection, tumor locations, mortality, or OS in univariate analyses.

\section{Progression-Free Interval and Overall Survival}

Data on tumor progression and mortality were available for 143 (88\%) and 161 (99\%) of 162 elderly patients, respectively, with a median follow-up of 90 months (range 0-242 months). A follow-up duration of $0(\leq 1)$ months was calculated for 7 patients $(4 \%)$ who died within 4 weeks after surgery and for $16(10 \%)$ who were lost to follow-up. Progression was observed in 16 patients (11\%), with a mean PFI for those patients of 187 months (median not reached at the time of analysis). Recurrences were treated with additional surgery in 12 patients (75\%), with 4 of these individuals also receiving additional radiation therapy. Stereotactic radiosurgery alone was performed for tumor recurrence in 2 cases $(12.5 \%)$, while further treatment remains unknown in the other 2 cases (12.5\%). Deaths were observed in 36 patients (22\%) with a median OS of 192 months (range 0-222 months, Tables 1 and 2). In $12(33 \%)$ of these cases the patients died during the perioperative period (within 3 months of surgery, see below); in the other 24 cases (67\%), the patients died during the subsequent follow-up period. In this latter group, the patients' status with respect to tumor recurrence was unknown in 3 cases (8\% of the 36 cases in which patients died); tumor recurrence had been documented in 6 cases (17\%); and in the remaining 15 patients (42\%) the cause of death was not documented, but there had been no evidence of tumor progression at follow-up. In univariate analyses, rates of recurrence were more than 3 times as high in male patients $(21 \%, 10 / 74)$ compared with female patients $(6 \%$, $6 / 96 ; p=0.011)$, and the mean PFI was correspondingly lower in males $(\mathrm{p}=0.014$, medians not reached, Fig. 1A). The median age at diagnosis did not correlate with tumor progression but was higher in patients who died during the follow-up period (74 vs 70 years, $\mathrm{p}=0.012$ ).
TABLE 2. Characteristics of elderly short- and long-term survivors ( $\leq 3$ months and $>3$ months) and individuals who died within 3 months after surgery*

\begin{tabular}{|c|c|c|c|c|}
\hline Characteristic & $\begin{array}{l}\text { Short-Term } \\
\text { Survivors }\end{array}$ & $\begin{array}{l}\text { Long-Term } \\
\text { Survivors }\end{array}$ & $\begin{array}{c}p \\
\text { Value }\end{array}$ & $\begin{array}{c}\text { 3-Mo } \\
\text { Mortality }\end{array}$ \\
\hline Age in yrs (median) & 75 & 69 & $0.001 \dagger$ & 80 \\
\hline Total no. of patients & $22(100)$ & $103(100)$ & & $12(100)$ \\
\hline Sex & & & NS & \\
\hline Female & $17(77)$ & $70(68)$ & & $8(67)$ \\
\hline Male & $5(23)$ & $33(32)$ & & $4(33)$ \\
\hline Tumor location & $22(100)$ & $103(100)$ & NS & $12(100)$ \\
\hline Convexity & $10(46)$ & $30(29)$ & & $10(84)$ \\
\hline Falx & $1(4)$ & $13(13)$ & & $1(8)$ \\
\hline Sphenoid ridge & $4(18)$ & $13(13)$ & & \\
\hline Posterior fossa & $1(4)$ & $11(10)$ & & \\
\hline Tuberculum sellae & $0(0)$ & $2(2)$ & & \\
\hline Frontobasal & $3(14)$ & $18(18)$ & & $1(8)$ \\
\hline Spinal & $3(14)$ & $14(13)$ & & \\
\hline Petroclival & $0(0)$ & $2(2)$ & & \\
\hline Intraventricular & $0(0)$ & $0(0)$ & & \\
\hline EOR, Simpson grade & $21(100)$ & $97(100)$ & NS & $11(100) \ddagger$ \\
\hline Grade I or II & $15(71)$ & $78(80)$ & & $9(82)$ \\
\hline Grade III or IV & $6(29)$ & $19(20)$ & & $2(18)$ \\
\hline WHO grade & $22(100)$ & $103(100)$ & NS & $12(100)$ \\
\hline Grade I & $18(82)$ & $90(87)$ & & $8(66)$ \\
\hline Grade II & $3(14)$ & $13(13)$ & & $1(8)$ \\
\hline Grade III & $1(4)$ & $0(0)$ & & $3(25)$ \\
\hline
\end{tabular}

* Comparison of baseline clinical variables, tumor location, WHO grade, and EOR in patients who were short- and long-term survivors-alive at last scheduled follow-up, $\leq 3$ months or $>3$ months after surgery, respectivelypresented with a summary of characteristics of individuals who died within 3 months after surgery.

$\dagger$ In univariate analyses.

$\ddagger$ Unknown in 1 patient.

\section{Grade of Resection and Prognosis}

Kaplan-Meier analyses revealed a mean PFI of 185, 206, 97, and 84 months in patients undergoing Simpson Grade I, II, III, and IV meningioma resection ( $p=0.033)$. When the cases were dichotomized into gross total resection (GTR, Simpson Grades I and II, $\mathrm{n}=104,77 \%$ ) and subtotal tumor resection (STR, Simpson Grades III and IV, $\mathrm{n}=32,23 \%$ ), $8(8 \%)$ of 104 patients with GTR and $8(25 \%)$ of 32 patients with STR were found to develop tumor recurrence during the course of clinical follow-up ( $p=0.023)$. The mean PFI after GTR was 197 months, which was significantly longer than after STR (99 months, p = 0.007, Fig. 1B; medians not reached). However, no correlation between grade of tumor resection and mortality or OS was found.

\section{Histology and Prognosis}

The median PFI was 83 months for patients with Grade II tumors and 58 months for those with Grade III tumors; the median PFI for Grade I tumors was not reached at the time of analyses ( $p<0.001$, Fig. 1C). Similarly, mortality 
A

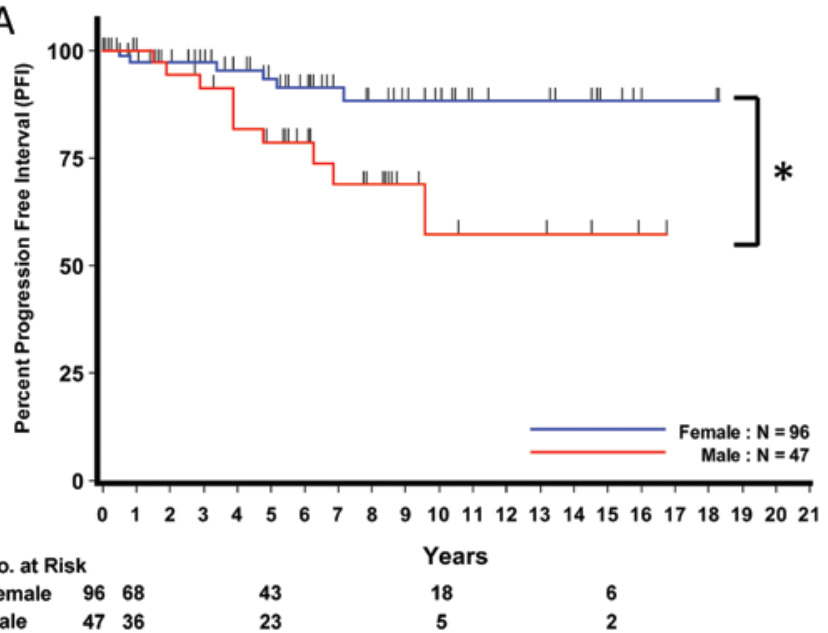

C

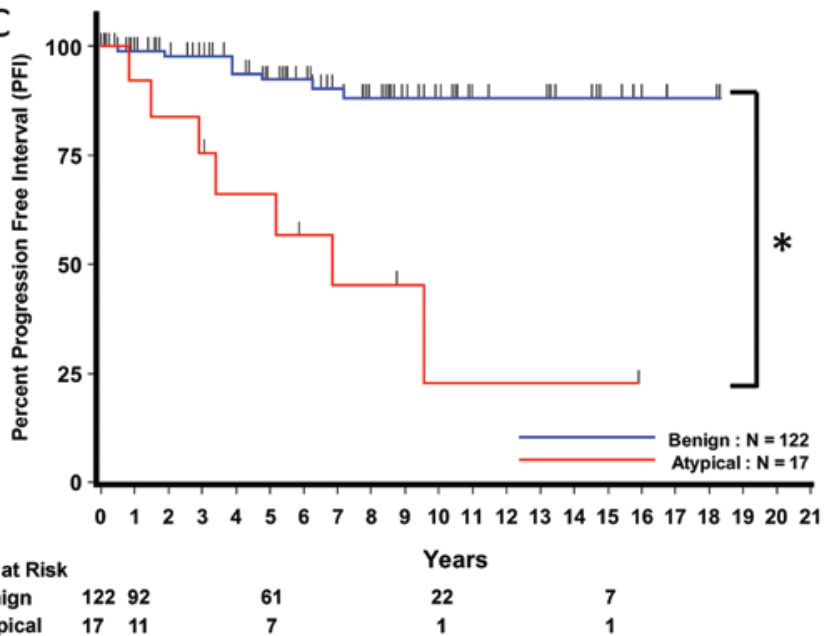

B

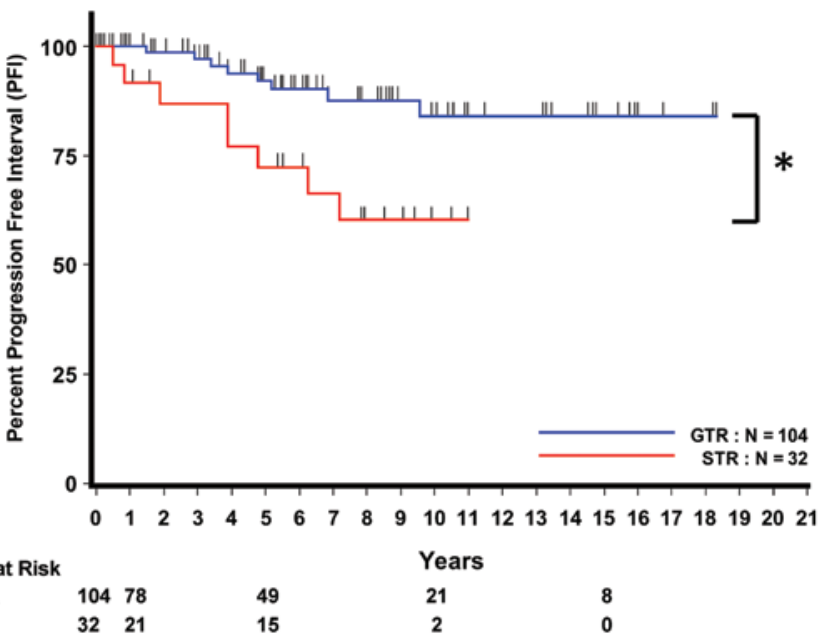

D

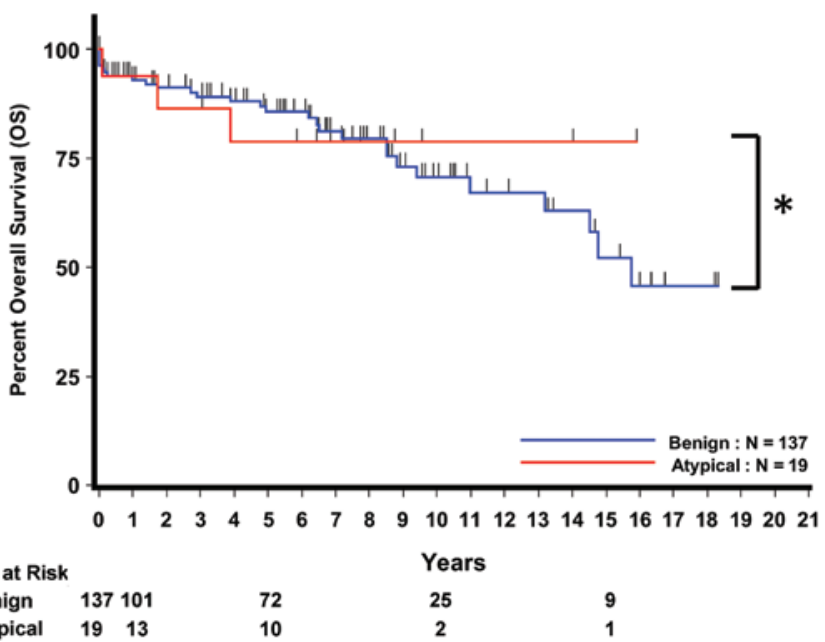

FIG. 1. Kaplan-Meier analyses of PFI (A-C) and OS (D) in elderly patients. The Mantel-Cox test revealed shorter PFI in males $(p=0.014, A)$ and distinctly prolonged PFI in patients undergoing GTR as compared with STR $(p=0.007, B)$. WHO grade was confirmed to be strongly predictive for both $\mathrm{PFI}(\mathrm{p}<0.001, \mathrm{C})$ and $\mathrm{OS}(\mathrm{p}<0.001, \mathrm{D})$. Numbers at risk at $0,1,5,10$, and 15 years after surgery are shown below the plots. ${ }^{*}$ Statistically significant $(p<0.05)$. Figure is available in color online only.

was found to increase with WHO tumor grade and was $21 \%$ in benign $(\mathrm{n}=29$ of 137$), 16 \%$ in atypical $(\mathrm{n}=3$ of 19 ), and $80 \%$ ( $n=4$ of 5$)$ in anaplastic meningiomas $(\mathrm{p}=$ 0.015 ). Kaplan-Meier analyses revealed a median OS of 191 months and 1 month in Grade I and III tumors, while the median was not reached in Grade II meningiomas (p $<0.001$, Fig. 1D). Data on histopathological tumor subtypes were available in all patients but did not correlate with outcome.

\section{Prognosis in Multivariate Analyses}

Cox regression analyses were performed for identifying independent predictors of outcome in terms of tumor progression and mortality among elderly patients. Thus, WHO Grade II or III (HR 24.74, 95\% CI 4.23-144.66) as well as STR (HR 10.57, 95\% CI 2.23-50.05) were found to independently correlate with lower PFI ( $p<0.001$ and $\mathrm{p}=0.003$, respectively). Higher age at diagnosis (HR 1.16, 95\% CI 1.08-1.25; p < 0.001) was independently corre- lated with lower OS, while a spinal tumor location was slightly correlated with longer survival (HR $0.22,95 \%$ CI $0.05-0.98 ; \mathrm{p}=0.047$ ).

\section{Comparative Survival Analyses of Elderly Meningioma Patients and Average Life Expectancy in Germany}

Age- and sex-adjusted life expectancy at the date of surgery was obtained from data published by the Federal Bureau of Statistics, Statistisches Bundesamt, Germany, for each individual patient. The median anticipated life expectancy would have been 168 months (14 years), which was comparable to median OS in elderly patients in our cohort. ${ }^{11}$ Population-based and Kaplan-Meier analyses revealed no significant differences of median survival in elderly patients undergoing meningioma surgery as compared with the average age- and sex-adjusted life expectancies in Germany (HR 1.03, 95\% CI 0.70-1.50, $\mathrm{p}=0.886$; Fig. 2). However, visual inspection of curves revealed a first phase with shorter than expected survival, which in- 
cluded patients who died during the first 3 months after surgery (early mortality). When excluding these patients, survival even more closely matched age- and sex-matched survival data for the general population (for males, HR $0.68,95 \%$ CI $0.31-1.46, \mathrm{p}=0.322$; and for females, $\mathrm{HR}$ $0.91,95 \%$ CI $0.53-1.57, \mathrm{p}=0.737$; Figs. $3 \mathrm{~A}$ and B). The median OS in older meningioma patients was shorter than anticipated with reference to the general population in 63 $(20.5 \%)$ of 161 patients and was shorter in high-grade tumors and patients of higher age in univariate analyses $(\mathrm{p}$ $=0.011$ and $p=0.001$, respectively). Multivariate analyses adjusted for sex, tumor location, and EOR confirmed increasing age (OR 1.087, 95\% CI 1.01-1.72, p = 0.031) to mildly and Grade III tumors (OR $12.21,95 \%$ CI 1.24 $120.40, \mathrm{p}=0.032$ ) to strongly and independently predict shorter median OS as compared with survival in the general population.

\section{Comparative Analyses of Older and Younger Meningioma Patients}

Comparative analyses were performed to identify clinical and histopathological differences between older (n $=162)$ and younger patients $(\mathrm{n}=338)$ undergoing initial resection of meningioma during the same inclusion period. The younger group included 93 males (27\%) and 245 females $(73 \%$, female/male ratio 2.6$)$ with a median age of 51 years (range 7-64 years). Among younger patients, baseline clinical data, tumor location, WHO grade, and histopathological subtypes were available in all and grade of resection in 315 individuals (93\%, Table 1). Of 333 patients with available data, 31 (9\%) received postoperative radiation therapy.

Univariate analyses revealed no differences in sex distribution between younger and older patients. Although the intracranial tumor location was similar in both groups, the frequency of spinal meningiomas was 3 times as high in older patients $(12 \%, 20 / 162)$ compared with younger patients $(4 \%, 13 / 338, \mathrm{p}=0.002$; Table 1$)$. There were no significant differences with respect to grades of tumor resection according to the Simpson classification system or after dichotomizing into GTR and STR, and similar frequencies of postoperative radiation therapy were observed. Comparing histopathological data, high-grade meningiomas were found to occur significantly more often among elderly patients. Thus, benign meningiomas were found in $85 \%$ of elderly patients $(n=138)$ and $92 \%$ of younger patients $(\mathrm{n}=312)$, atypical meningiomas were found in $12 \%$ of elderly patients $(\mathrm{n}=19)$ and $7 \%$ of younger patients $(\mathrm{n}=$ 25 ), and anaplastic tumors were found in $3 \%$ of elderly patients $(n=5)$ and $0.3 \%$ of younger patients (n 1) $(p=0.006$, Fig. 4A). Correspondingly, the median age at diagnosis was 56 years in Grade I, 57 years in Grade II, and 75 years in Grade III tumors ( $\mathrm{p}=0.003$, Fig. 4B). The frequency of histopathological subtypes of Grade I meningiomas did not differ significantly between the 2 groups (Table 1).

\section{Comparison of Outcome in Elderly and Younger Patients}

With a median follow-up of 90 months (range 0-242 months), cumulative data concerning mortality and recurrence were available in 499 (99\%) and $456(93 \%)$ of 500 patients, respectively. The rate of recurrence as well as

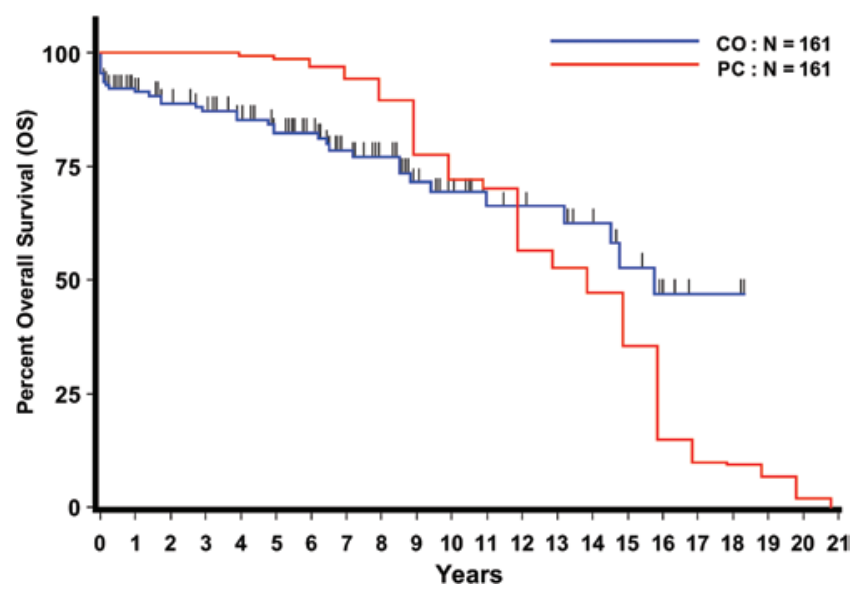

FIG. 2. Kaplan-Meier analyses comparing rates of survival in elderly patients in our cohort (CO) with life expectancy of the German population (PC, population controls). Although apparently higher mortality at 3 months depicts an increased perioperative risk, analysis revealed no statistically significant difference in survival (HR 1.03, 95\% Cl 0.70-1.50, $p=0.886)$. Figure is available in color online only.

PFI were found to be similar in the elderly and younger patient groups (Fig. 4C). However, the mortality rate was considerably higher in patients 65 years or older than in younger patients $(22 \%$ [36/161] vs $6 \%$ [19/338], p < 0.001) with correspondingly shorter OS in elderly (median 191 months) as compared with younger patients (median not reached, $\mathrm{p}<0.001$ ). The 3 -month perioperative mortality was $7 \%$ in elderly and $1 \%$ in younger patients (OR 8.171, 95\% CI 2.245-29.747, p = 0.001, Fig. 4D and Table 1). Multivariate regression analyses confirmed lower PFI after STR (HR 2.20, 95\% CI 1.32-3.67, p = 0.002) and among patients with high-grade meningiomas (HR 6.37, 95\% CI $3.61-11.22, \mathrm{p}<0.001$ ) but revealed no correlation between patients' age and tumor recurrence. Moreover, age at diagnosis of 65 years and older was found to independently correlate with increased mortality during clinical followup (HR 4.9, 95\% CI 2.75-8.74, p < 0.001).

\section{Short-Term and Long-Term Mortality in Elderly Patients}

Tables 2 and 3 summarize characteristics and causes of mortality of elderly short- and long-term survivors $(\leq 3$ months and $>3$ months, respectively) and individuals who died within 3 months after surgery. Analysis of symptoms at the time of surgery revealed a considerably high portion of severe neurological deficits (e.g., hemiparesis or reduced consciousness). Moreover, most of the individuals had numerous preoperative comorbidities. The causes of early postoperative death were known in 6 patients $(50 \%)$ and included brain edema $(\mathrm{n}=2)$, subdural $(\mathrm{n}=1)$ and intracerebral $(\mathrm{n}=1)$ hematomas, and cardiac $(\mathrm{n}=1)$ and respiratory $(n=1)$ deterioration. Separate analyses were performed in older patients for identifying variables correlated with death within 3 months after surgery and during long-term follow-up. Thus, perioperative death $(n=12)$ was found to be independent of patients' age, sex, tumor location, grade of resection, and WHO grade on both uni- and multivariate analyses. On long-term follow-up, the median age at diagnosis was slightly lower in survivors (69 years) than 

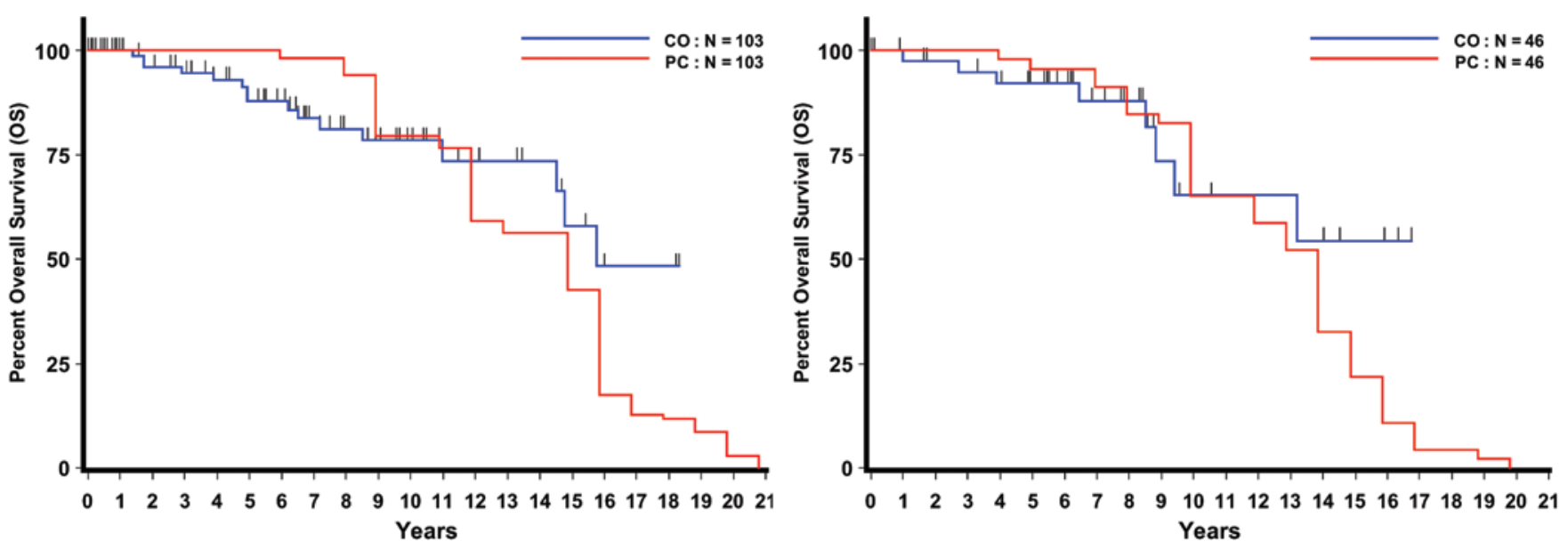

FIG. 3. Kaplan-Meier curves comparing survival of female (left) and male (right) patients in our cohort with age-and sex-adjusted life expectancy of the German population. Survival remained equal in both groups after exclusion of the 3-month perioperative mortality (males, HR 0.68, 95\% Cl 0.31-1.46, $p=0.322$; females, HR 0.91, 95\% Cl 0.53-1.57, $p=0.737$ ). Figure is available in color online only.

in patients who died (80 years, $\mathrm{p}=0.019)$ and the median OS was shorter in patients with anaplastic meningiomas (60 months) than in those with benign meningiomas (191 months), whereas it was not reached for patients with Grade II tumors at the time of the analyses $(\mathrm{p}=0.025)$. Moreover, the median OS after STR was 114 months, and the median was not reached for individuals who underwent GTR ( $p$ $=0.041)$. Cox regression multivariate analyses confirmed higher age (HR 1.16, 95\% CI 1.06-1.28, $\mathrm{p}=0.002)$ and STR (OR 2.7, 95\% CI 1.09-6.69, $\mathrm{p}=0.032$ ) as independent predictors of shorter OS on long-term follow-up.

\section{Discussion}

Due to increasing life expectancy, the treatment of meningiomas in elderly patients has become an everyday issue in neurosurgical practice. Correspondingly, one-third of patients in our cohort were 65 years or older, and the frequency of surgery in older patients increased more than $10 \%$ within the 15 -year inclusion period. As older individuals are frequently in a poor preoperative medical condition and suffer increased early perioperative morbidity and mortality, more information regarding the long-term benefits of surgery is required for justifying surgical treatment in these patients. Several studies have indicated that increased age, male sex, low Karnofsky Performance Status and Barthel index, concomitant diseases, and preoperative severe neurological deficits as well as several radiological criteria (e.g., tumor size, number of lesions, peritumoral edema, sinus involvement) predict poor clinical outcome after meningioma surgery. $5,6,8,9,14,20$ However, the question of increased perioperative mortality in elderly patients is still under discussion. ${ }^{3-5,14,16,20,23,25}$ Conversely, the risks of a wait-and-see strategy in the elderly should not be underestimated, because the patient's medical condition is not likely to improve after diagnosis, and tumor-related mortality was shown to be increased for patients who received conservative treatment as compared with those who underwent resection. ${ }^{1}$ Although increased mortality in el- derly patients and in patients treated conservatively has been confirmed in larger epidemiological studies, selection bias in terms of considering healthier individuals for surgery might contribute to the better prognosis in surgically treated patients. Moreover, although including about 9000-12,000 patients, other investigations have not been focused on analyzing elderly patients, lack disease-specific mortality and detailed clinical information (e.g., tumor location or standardized evaluation of degree of resection), and are limited with respect to median duration of followup (e.g., only 1 year in one study). ${ }^{5,20}$ Hence, it is unclear whether increasing age contributes to increased mortality in elderly patients with slow-growing meningiomas.

\section{Subgroup Analyses of Elderly Patients}

Rates of recurrence and mortality in our analyses were similar to those reported in most studies of older patients. $3,7,8,18,25,26$ Moreover, our study confirmed previously published findings in younger ${ }^{5,20,24,31}$ and elderly patients ${ }^{8}$ of a worse prognosis in males as compared with females, basically due to a 3 -fold increased rate of recurrence and lower PFI, while rates of mortality and OS were found to be similar. As WHO grade-but not tumor location, grade of resection, or age-was found to be correlated with patients' sex ( $p=0.046$; data not shown), this difference in prognosis might be largely explained by an increased portion of atypical and anaplastic meningiomas in male elderly patients. ${ }^{22,24}$

Increased median age at diagnosis was independently correlated with worse prognosis in that elderly patients had a higher mortality rate and shorter OS than younger patients. Although this confirms previously published findings, ${ }^{5,20}$ it appears reasonable to assume that this observation is biased by the naturally limited life expectancy of elderly patients. Indeed, comparisons of median OS revealed no significant difference between older patients in our cohort (192 months [16 years], median age 71) and the reported average life expectancy ( 15.5 years) of the German population of the same age (HR 1.03, $\mathrm{p}=0.886$, Fig. 
A

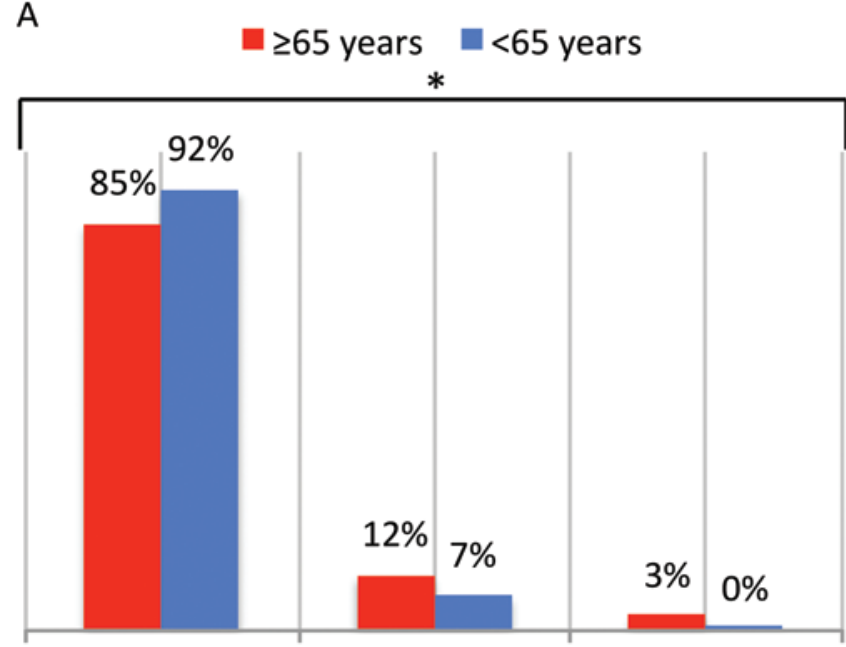

WHO grade I WHO grade II WHO grade III

C

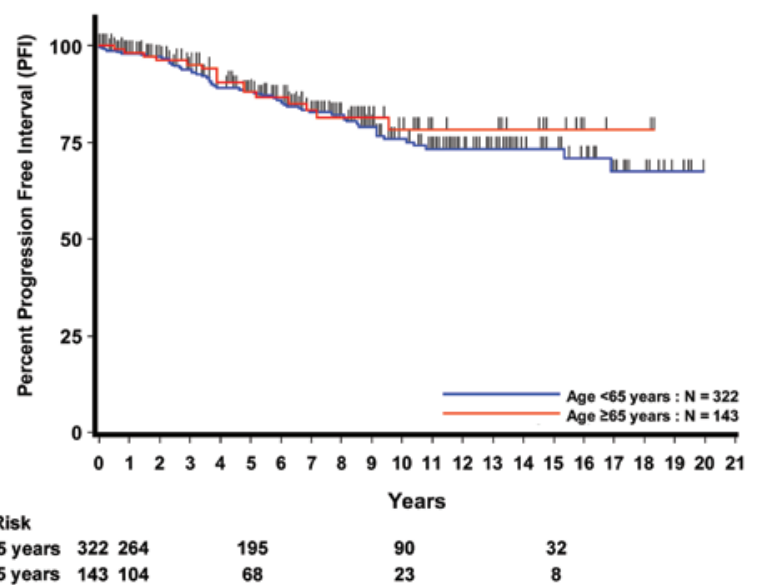

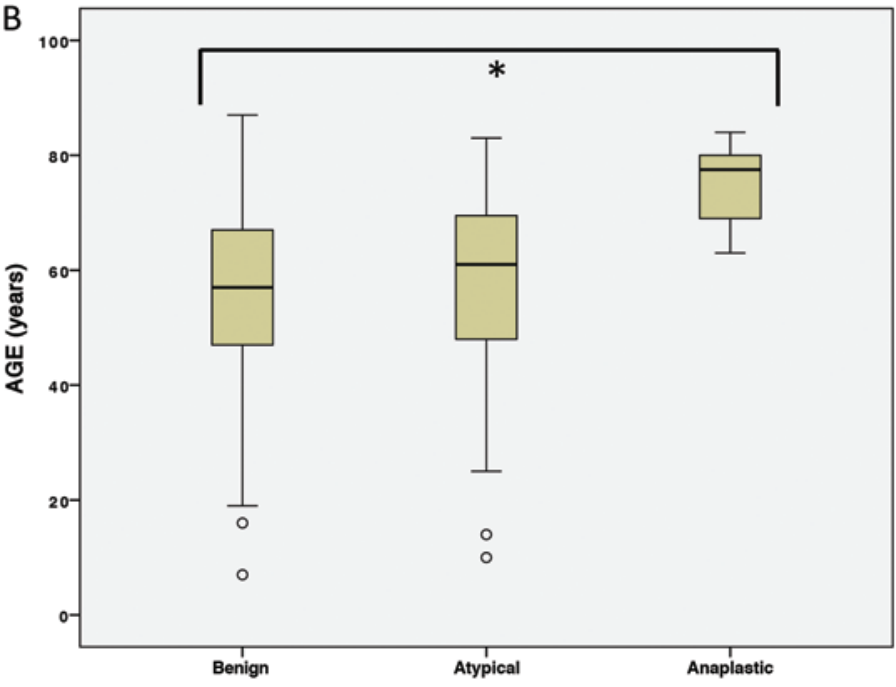

Meningioma grading

D

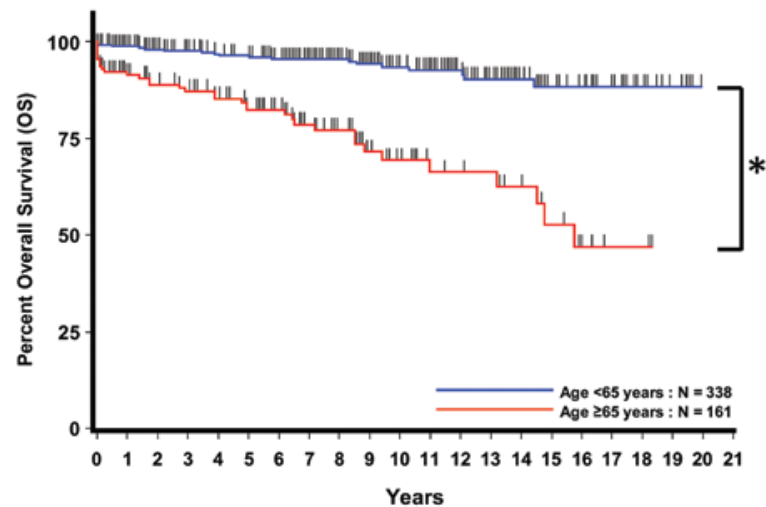

No. at Risk

$\begin{array}{lll}225 & 113 & 38 \\ 82 & 27 & 0\end{array}$

FIG. 4. Comparative analyses of cases involving elderly ( $\geq 65$ years) and younger ( $<65$ years) patients. The bar graph (A) shows increased frequency of high-grade meningioma among elderly patients $(p=0.006)$, and the box and whiskers plot $(B)$ shows that median age is correlated to WHO grade $(p=0.003)$. (The boxes indicate the interquartile range, the whiskers the minimum and maximum values, and the heavy horizontal line indicates the median.) The Kaplan-Meier curves show that the rates of recurrence in older $(17 \%, n=16)$ and younger $(11 \%, n=55)$ patients and PFI are similar $(\mathbf{C})$ but that OS is shorter in older as compared with younger individuals $(p=0.001, \mathrm{D})$. Thus, the 3 -month perioperative mortality is $7 \%$ in elderly patients but only $1 \%$ in younger patients after both univariate (12 of 161 and 3 of 338 , respectively, $p<0.001$ ) and multivariate (OR $8.171,95 \% \mathrm{Cl} 2.245-29.747$, $p$ $=0.001$ ) analyses. Numbers at risk at $0,1,5,10$, and 15 years after surgery are shown below the Kaplan-Meier plots. ${ }^{*}$ Statistically significant $(p<0.05)$. Figure is available in color online only.

2). In contrast, OS in younger patients was, as expected, found to be shorter than that of the age- and sex-matched population $^{12}$ (medians not reached, HR $4.08,95 \%$ CI $2.08-8.0 ; \mathrm{p}<0.001)$. This observation remained stable even after exclusion of WHO Grade II and III tumors (HR $3.87,95 \%$ CI 1.94-7.73). The considerably higher 3-month mortality among elderly patients undergoing surgery as compared with both the German sex- and age-matched population (Fig. 3) and younger patients (OR 8.171, 95\% CI 2.245-29.747; $\mathrm{p}=0.001$ ) emphasizes a distinctly increased perioperative risk. Thus, although the numbers of patients and available clinical data were not sufficient for statistical analyses, there appears to have been a considerable amount of preoperative morbidity among these patients (Table 3 ). As we found no correlation with other variables in our analyses, these findings suggest that the presence of comorbidities and poor preoperative medical status contribute to the increased mortality in this context. ${ }^{6,8,9,14}$ On the other hand, our findings of a distinctly prolonged life expectancy after GTR might indicate that with thorough perioperative risk stratification and careful management, maximal safe tumor resection is beneficial also in elderly patients. However, as patients were not randomized to either conservative or surgical treatment, it remains unclear whether this observation was partially influenced by a preference for surgical treatment for healthier patients and not for patients with severe comorbidities. Importantly, time to progression was not significantly shorter in older patients.

Interestingly, we found a high proportion of spinal meningiomas in elderly patients that were exclusively WHO 
TABLE 3. Causes of 3-month postoperative mortality and patients' individual characteristics

\begin{tabular}{|c|c|c|c|c|c|c|c|c|}
\hline $\begin{array}{l}\text { Case } \\
\text { No. }\end{array}$ & $\begin{array}{l}\text { Age (yrs), } \\
\text { Sex }\end{array}$ & $\begin{array}{l}\text { Tumor } \\
\text { Location }\end{array}$ & EOR & $\begin{array}{l}\text { WHO } \\
\text { Grade }\end{array}$ & Cause of Death $\dagger$ & $\begin{array}{c}\text { OS } \\
\text { (mos) }\end{array}$ & Comorbidities* & Symptoms* \\
\hline 1 & $81, \mathrm{~F}$ & Convexity & Unk & 1 & $\mathrm{SDH}$ & 0 & $\mathrm{CHD}$ & $\begin{array}{l}\text { Reduced LOC, focal neurol } \\
\text { deficits }\end{array}$ \\
\hline 2 & $74, \mathrm{M}$ & Frontobasal & GTR & 1 & Unk & 0 & DM & None \\
\hline 3 & $66, F$ & Convexity & GTR & 1 & Unk & 0 & $\begin{array}{l}\text { CHD, cardiac arrhythmia, RI, hypothyreo- } \\
\text { sis, } 3 \text { others }\end{array}$ & $\begin{array}{l}\text { HA, focal neurol deficits, } \\
\text { other }\end{array}$ \\
\hline 4 & $73, \mathrm{~F}$ & Convexity & GTR & 1 & $\mathrm{ICH}$ & 0 & CHD, DM, other & $\begin{array}{l}\text { HA, focal neurol deficits, } \\
\text { other }\end{array}$ \\
\hline 5 & $80, F$ & Convexity & STR & 3 & $\begin{array}{l}\text { Malignant brain } \\
\text { edema }\end{array}$ & 0 & $\mathrm{Cl}, 2$ others & Focal neurol deficits \\
\hline 6 & $80, \mathrm{M}$ & Convexity & STR & 3 & Unk & 0 & Malignant neoplasm & Focal neurol deficits \\
\hline 7 & $81, \mathrm{M}$ & Convexity & GTR & 2 & Unk & 1 & CHD, cardiac arrhythmia, 2 others & $\begin{array}{l}\text { Focal neurol deficits, } \mathrm{CN} \\
\text { deficits, other }\end{array}$ \\
\hline 8 & $65, M$ & Convexity & GTR & 1 & $\begin{array}{l}\text { Cardiac decom- } \\
\text { pensation }\end{array}$ & 2 & $\begin{array}{l}\text { CHD, cardiac arrhythmia, RI, } 3 \text { malignant } \\
\text { neoplasms, AHT, hypercholesterolemia, } \\
3 \text { others }\end{array}$ & Sz \\
\hline 9 & $67, \mathrm{~F}$ & Convexity & GTR & 1 & Unk & 3 & None & Reduced LOC, Sz \\
\hline 10 & $84, F$ & Convexity & GTR & 3 & $\begin{array}{l}\text { Malignant brain } \\
\text { edema }\end{array}$ & 1 & $\mathrm{RI}, \mathrm{AHT}$ & Focal neurol deficits, other \\
\hline 11 & $79, \mathrm{~F}$ & Falx cerebri & GTR & 1 & $\begin{array}{l}\text { Pneumonia/resp } \\
\text { failure }\end{array}$ & 0 & $\mathrm{RI}$ & $\begin{array}{l}\text { Reduced LOC, focal neurol } \\
\text { deficits, Sz }\end{array}$ \\
\hline 12 & $80, \mathrm{~F}$ & Convexity & GTR & 1 & Unk & 1 & $\begin{array}{l}\mathrm{CHD} \text {, DM, cardiac arrhythmia, AHT, hyper- } \\
\text { cholesterolemia, } 2 \text { others }\end{array}$ & Vertigo, other \\
\hline
\end{tabular}

$\mathrm{AHT}=$ arterial hypertension; $\mathrm{CHD}=$ coronary heart disease; $\mathrm{Cl}=$ cardiac insufficiency; $\mathrm{CN}=$ cranial nerve; $\mathrm{DM}=$ diabetes mellitus; $\mathrm{HA}=$ headache; $\mathrm{ICH}=$ intracerebral hematoma; $L O C=$ level of consciousness; neurol = neurological; resp = respiratory; RI = renal insufficiency; SDH = subdural hematoma; Sz = seizures; Unk = unknown. * At the time of diagnosis.

$\dagger$ Cause of death was available in $6(50 \%)$ of 12 of individuals who died within 3 months after surgery.

Grade I tumors with a consequently good prognosis. Although an increased incidence of mostly benign spinal meningiomas has previously been reported in elderly patients, ${ }^{17}$ this finding is noteworthy in light of an overall increased number of high-grade tumors in these patients..$^{10,22}$ Moreover, grade of resection was independent of all analyzed variables, including tumor location, but correlated with recurrence rates and PFI. Thus, basically confirming observations in younger cohorts, ${ }^{24,28}$ sufficient tumor resection was shown to be achievable in most of the elderly patients independent of tumor location and to be correlated with improved PFI. Interestingly, both early mortality and OS were independent of grade of resection and tumor location in our analyses. As previously published studies with shorter follow-up periods also reported that mortality and functional outcome did not correlate with grade of resection in older patients, $, 7,25$ these findings further encourage consideration of maximum safe meningioma resection in older patients.

Concerning histopathological data, our findings further confirm results reported for younger patients. Thus, distribution of WHO grades was similar to rates reported for younger patients ${ }^{24}$ and grading was correspondingly found to be strongly prognostic in terms of recurrence, PFI, and OS. Similar to previous reports, ${ }^{10,27}$ univariate analyses in our study revealed a higher proportion of high-grade meningiomas at the convexity and along the falx cerebelli, whereas skull base and spinal meningiomas were mostly found to be benign.

\section{Comparative Analyses of Elderly and Younger Patients}

Sex distribution and intracranial tumor location were equivalent in elderly and younger patients, and no significant differences were found with respect to treatment in terms of extension of tumor resection or postoperative radiation therapy. Histopathological subtypes were mostly similar in the 2 groups, but the frequency of high-grade meningiomas was increased in elderly patients $(15 \%$ vs $7.3 \%$, Fig. 4A and B). These findings match observations by other groups. ${ }^{10,22}$

Interestingly, recurrence rates were similar in the 2 patient groups. As younger patients are considered to have a higher likelihood for developing recurrences due to their longer life expectancy, the lack of differences in recurrence rates between the groups is remarkable and, to the best of our knowledge, has not been reported previously. Because tumor location and treatment were similar in the 2 groups, these findings indicate a similar biological behavior of most (low-grade) meningiomas in younger and elderly patients. Moreover, these findings might further confirm the importance of achieving maximum safe resection independent of patients' age.

We are aware of limitations of our study. Despite complete follow-up data in the vast majority of patients, we 
did not have data on perioperative medical conditions for all patients. Comorbidities and data on tumor recurrence and mortality do not allow conclusions regarding quality of life and (surgery-related) morbidity. Due to the length of the follow-up period, data on adjuvant radiation therapy were possibly incomplete and, since we focused on the surgical treatment, registered in too little detail to allow further inclusions to statistical analyses. This might have led to underreporting of adjuvant radiation therapy especially in cases of high-grade lesions. As we did not perform randomization and as data on conservatively treated patients (i.e., those treated with stereotactic radiosurgery or those whose condition was managed with observation only) are lacking, this might lead to a selection bias in terms of considering healthier older patients for surgery. On the other hand, according to Table 3, severe comorbidities were not generally considered contraindications for surgery. We tried to minimize the effect of selection bias by performing population-based analyses. Concerning outcome analyses, although follow-up imaging was critically reviewed according to previously published studies ${ }^{29}$ by at least 1 neurosurgeon and a radiologist, progression was not defined in a standardized manner (e.g., according to the Response Evaluation Criteria in Solid Tumors [RECIST]). As the cause death was unknown in $42 \%$ of the patients, mortality in our series does not distinguish tumor-related from non-tumor-related mortality, which probably increased mortality rates and obscured the true rates of tumor-related death. However, we tried to minimize this effect by performing comparative Kaplan-Meier analyses using survival data from a "nonmeningioma" population. Finally, although the length of the inclusion period allowed both a large patient cohort and long-term follow-up, our analysis suffers the limitations of its retrospective nature and the fact that tumors were diagnosed according to $3 \mathrm{WHO}$ classifications. However, as shown above, the frequency of high-grade meningiomas did not significantly change within the inclusion period. Additionally, the influences of new operative techniques (e.g., intraoperative imaging or cranial navigation) within the 15year inclusion period cannot be determined from our data.

\section{Conclusions}

In conclusion, we here present a large series of patients with almost complete information on clinical, histopathological, and radiological variables and follow-up data. We showed an increasing portion of patients 65 years and older in daily neurosurgical practice with both PFI and recurrence rates comparable to younger individuals but with increased incidence of high-grade lesions. For older patients we showed that, despite an increased perioperative mortality in a high-risk subgroup with a probably poor medical condition, maximum achievable tumor resection enables both prolonged PFI and OS. Our findings suggest that after thorough preoperative risk stratification, careful and maximum tumor resection should be attempted also in older patients with meningioma.

\section{Acknowledgments}

Funding for this research was provided by the Maria Möller
Stiftung (recipient: B.B.). The funder was not involved in design of the study, laboratory research, or analysis of the results.

\section{References}

1. Arienta C, Caroli M, Balbi S: Intracranial meningiomas in patients over 70 years old. Follow-up in operated and unoperated cases. Aging (Milano) 4:29-33, 1992

2. Baldi I, Engelhardt J, Bonnet C, Bauchet L, Berteaud E, Grüber A, et al: Epidemiology of meningiomas. Neurochirurgie [epub ahead of print], 2014

3. Bateman BT, Pile-Spellman J, Gutin PH, Berman MF: Meningioma resection in the elderly: nationwide inpatient sample, 1998-2002. Neurosurgery 57:866-872, 2005

4. Black P, Kathiresan S, Chung W: Meningioma surgery in the elderly: a case-control study assessing morbidity and mortality. Acta Neurochir (Wien) 140:1013-1017, 1998

5. Cahill KS, Claus EB: Treatment and survival of patients with nonmalignant intracranial meningioma: results from the Surveillance, Epidemiology, and End Results Program of the National Cancer Institute. Clinical article. J Neurosurg 115:259-267, 2011

6. Caroli M, Locatelli M, Prada F, Beretta F, Martinelli-Boneschi F, Campanella R, et al: Surgery for intracranial meningiomas in the elderly: a clinical-radiological grading system as a predictor of outcome. J Neurosurg 102:290-294, 2005

7. Chen ZY, Zheng CH, Tang Li, Su XY, Lu GH, Zhang CY, et al: Intracranial meningioma surgery in the elderly (over 65 years): prognostic factors and outcome. Acta Neurochir (Wien) 157:1549-1557, 2015

8. Cohen-Inbar O, Soustiel JF, Zaaroor M: Meningiomas in the elderly, the surgical benefit and a new scoring system. Acta Neurochir (Wien) 152:87-97, 2010

9. Cohen-Inbar O, Sviri GE, Soustiel JF, Zaaroor M: The Geriatric Scoring System (GSS) in meningioma patients - validation. Acta Neurochir (Wien) 153:1501-1508, 2011

10. Cornelius JF, Slotty PJ, Steiger HJ, Hänggi D, Polivka M, George B: Malignant potential of skull base versus non-skull base meningiomas: clinical series of 1,663 cases. Acta Neurochir (Wien) 155:407-413, 2013

11. Destatis: Durchschnittliche weitere Lebenserwartung nach Altersstufen. Wiesbaden, Germany: Statistisches Bundesamt Deutschland, 2015 (https://www.destatis.de/DE/ ZahlenFakten/GesellschaftStaat/Bevoelkerung/Sterbefaelle/ Tabellen/Lebenserwartung.pdf?__blob=publicationFile) [Accessed March 14, 2016]

12. Destatis: Sterbefälle, Lebenserwartung. Wiesbaden, Germany: Statistisches Bundesamt Deutschland, 2015 (https://www.destatis.de/DE/ZahlenFakten/ GesellschaftStaat/Bevoelkerung/Sterbefaelle/Sterbefaelle. html) [Accessed March 14, 2016]

13. Dolecek TA, Dressler EV, Thakkar JP, Liu M, Al-Qaisi A, Villano JL: Epidemiology of meningiomas post-Public Law 107-206: The Benign Brain Tumor Cancer Registries Amendment Act. Cancer 121:2400-2410, 2015

14. Grossman R, Mukherjee D, Chang DC, Bennett R, Brem $\mathrm{H}$, Olivi A, et al: Preoperative Charlson comorbidity score predicts postoperative outcomes among older intracranial meningioma patients. World Neurosurg 75:279-285, 2011

15. Kleihues P, Burger PC, Scheithauer BW: Histological typing of tumours of the central nervous system, in Sobin LH (ed): World Health Organization International Classification of Tumours. Berlin: Springer, 1993, pp 33-37

16. Konglund A, Rogne SG, Helseth E, Meling TR: Meningioma surgery in the very old-validating prognostic scoring systems. Acta Neurochir (Wien) 155:2263-2271, 2013

17. Kshettry VR, Hsieh JK, Ostrom QT, Kruchko C, Benzel EC, Barnholtz-Sloan JS: Descriptive epidemiology of spinal 
meningiomas in the United States. Spine (Phila Pa 1976) 40:E886-E889, 2015

18. Lieu AS, Howng SL: Surgical treatment of intracranial meningiomas in geriatric patients. Kaohsiung J Med Sci 14:498-503, 1998

19. Louis DN, Scheithauer BW, Budka H, von Deimling A, Kepes JJ: Meningiomas, in Kleihues P, Cavenee WK (eds): Pathology and Genetics: Tumours of the Nervous System. Lyon: IARC Press, 2000, pp 176-184

20. McCarthy BJ, Davis FG, Freels S, Surawicz TS, Damek DM, Grutsch J, et al: Factors associated with survival in patients with meningioma. J Neurosurg 88:831-839, 1998

21. Ostrom QT, Gittleman H, Farah P, Ondracek A, Chen Y, Wolinsky Y, et al: CBTRUS statistical report: Primary brain and central nervous system tumors diagnosed in the United States in 2006-2010. Neuro Oncol 15 (Suppl 2):ii1-ii56, 2013

22. Park JS, Sade B, Oya S, Kim CG, Lee JH: The influence of age on the histological grading of meningiomas. Neurosurg Rev 37:425-429, 2014

23. Patil CG, Veeravagu A, Lad SP, Boakye M: Craniotomy for resection of meningioma in the elderly: a multicentre, prospective analysis from the National Surgical Quality Improvement Program. J Neurol Neurosurg Psychiatry 81:502-505, 2010

24. Perry A, Louis DN, Scheithauer BW, Budka H, von Deimling A: Meningiomas, in Louis DN, Ohgaki H, Wiestler OD, Cavenee WK (eds): WHO Classification of Tumors of the Central Nervous System. Lyon: International Agency on Cancer Research, 2007, pp 164-172

25. Poon MT, Fung LH, Pu JK, Leung GK: Outcome comparison between younger and older patients undergoing intracranial meningioma resections. J Neurooncol 114:219-227, 2013

26. Poon MT, Fung LH, Pu JK, Leung GK: Outcome of elderly patients undergoing intracranial meningioma resectiona systematic review and meta-analysis. Br J Neurosurg 28:303-309, 2014

27. Sade B, Chahlavi A, Krishnaney A, Nagel S, Choi E, Lee JH: World Health Organization Grades II and III meningiomas are rare in the cranial base and spine. Neurosurgery 61:1194-1198, 2007

28. Simpson D: The recurrence of intracranial meningiomas after surgical treatment. J Neurol Neurosurg Psychiatry 20:22-39, 1957

29. Starke RM, Przybylowski CJ, Sugoto M, Fezeu F, Awad AJ, Ding D, et al: Gamma Knife radiosurgery of large skull base meningiomas. J Neurosurg 122:363-372, 2015

30. Villalpando-Navarrete E, Rosas-Peralta VH, SandovalBalanzario MA: [Prognostic factors in elderly patient meningioma.] Rev Med Inst Mex Seguro Soc 52:530-537, 2014 (Span)

31. Westwick HJ, Shamji MF: Effects of sex on the incidence and prognosis of spinal meningiomas: a Surveillance, Epidemiology, and End Results study. J Neurosurg Spine 23:368-373, 2015

32. Zeng L, Wang L, Ye F, Chen J, Lei T, Chen J: Clinical characteristics of patients with asymptomatic intracranial meningiomas and results of their surgical management. Neurosurg Rev 38:481-488, 2015

\section{Disclosures}

The authors report no conflict of interest concerning the materials or methods used in this study or the findings specified in this paper.

\section{Author Contributions}

Conception and design: Brokinkel, Wölfer, Stummer. Acquisition of data: Holling, Spille, Heß. Analysis and interpretation of data: Brokinkel, Paulus, Stummer. Drafting the article: Brokinkel. Critically revising the article: Holling, Bleimüller, Stummer. Reviewed submitted version of manuscript: Brokinkel, Holling, Wölfer, Stummer. Approved the final version of the manuscript on behalf of all authors: Brokinkel. Statistical analysis: Brokinkel, Sauerland. Administrative/technical/material support: Heß, Paulus. Study supervision: Holling, Bleimüller, Wölfer, Stummer.

\section{Correspondence}

Benjamin Brokinkel, Department of Neurosurgery, University Hospital Münster, Albert-Schweitzer-Campus 1, Building A1, Münster 48149, Germany. email: benjamin.brokinkel@ ukmuenster.de. 